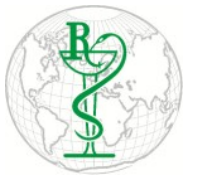

INDO GLOBAL JOURNAL OF

\title{
Heavy Metal Toxicity
}

\author{
Jhumi Jain, Sakshi Bajpai, Pammi Gauba * \\ Department of Biotechnology, Jaypee Institute of Information Technology, Noida, Uttar Pradesh, India
}

Address for Correspondance: Pammi Gauba, pammigauba@hotmail.com

Keywords Heavy

Metal Toxicity;

Environmental

Contamination;

Health Disorders.

\begin{abstract}
Heavy metal toxicity leads to major threats to the environment, leading to adverse effect on plants and human health. From thousands of years, heavy metals are been used up by the humans. However, threatening health disorders of heavy metals have been known, but still exposure and threats to heavy metal continuous. The increased global population, industrialization and urbanization are some of the major reasons to contaminate the environment. The release of heavy metals occurs from various anthropogenic activities, agronomic practices and dumping of various types of wastes. Heavy metals such as arsenic (As), mercury $(\mathrm{Hg})$, lead $(\mathrm{Pb})$ and cadmium $(\mathrm{Cd})$ are the most toxic heavy metals, according to WHO ranking of the top ten heavy metals. These heavy metals are considered to be intermineable and bio-accumulative in nature, so, do not get readily metabolized, thus remain accumulated in soils and plants. These heavy metals alter the food chain by disturbing the biochemical apparatus of the living organisms, thus affecting plants, affecting nutritive value of the produce and leading to life threatening disorders in humans. This paper reviews the impact of top four heavy metals (according to WHO); arsenic (As), mercury $(\mathrm{Hg})$, lead $(\mathrm{Pb})$ and cadmium $(\mathrm{Cd})$ on the plants and humans and also removal of these toxic metals by physical potent applications. (C) 2016 iGlobal Research and Publishing Foundation. All rights reserved.
\end{abstract}

Conference Proceedings: International Conference on Advances in Plant and Microbial Biotechnology (PMB-2017); JIIT, Noida: February 02-04, 2017

Indo Global Journal of Pharmaceutical Sciences( ISSN 22491023 ; CODEN- IGJPAI; NLM ID: 101610675) indexed and abstracted in EMBASE(Elsevier), SCIRUS(Elsevier),CABI, CAB Abstracts, Chemical Abstract Services(CAS), American Chemical Society(ACS), Index Copernicus, EBSCO, DOAJ, Google Scholar and many more. For further details, visit http://iglobaljournal.com 